\title{
Nanostructure Distribution and Strengthening Mechanisms in the Interface Regions of Al-Zn/Al-Mg Multilayered Composites
}

\author{
Shan $\operatorname{Lin}^{1, * 1}$, Hiroshi Okuda ${ }^{1}$, Katsushi Matsumoto ${ }^{2}$, Masahiro Yamaguchi ${ }^{2, * 2}$ and Kazufumi Sato ${ }^{2, * 2}$ \\ ${ }^{1}$ Department of Materials Science and Engineering, Kyoto University, Kyoto 606-8501, Japan \\ ${ }^{2}$ Materials Research Laboratory, Kobe Steel, Ltd., Kobe 651-2271, Japan
}

\begin{abstract}
In this study, we examined the distribution of nanostructures in the interdiffusion layer of $\mathrm{Al}-\mathrm{Mg} / \mathrm{Al}-\mathrm{Zn} / \mathrm{Al}-\mathrm{Mg}$ multilayer composites with different layer width via microbeam small-angle X-ray scattering (SAXS) measurements and direct observation using transmission electron microscopy (TEM). The changes in scattering profiles across the graded interfacial layers reflected the spatial change in the volume fraction, average size of precipitates, and their distribution in the sample. Microstructural parameters obtained from the SAXS analysis were used to explain the local hardness change in the interface area. Within the single interdiffusion layer of $\mathrm{Al}-\mathrm{Zn}-\mathrm{Mg}$ alloy, both of the Orowan and cutthrough mechanisms were observed. TEM imaging was used with the same projection of SAXS to analyze the various shapes of the precipitates to explain the anisotropy in the 2-dimensional scattered intensity measured via SAXS. The present results revealed the spatial distribution of nanostructures with averaged parameters and explained the local mechanical properties within the interface region of the multilayer composite sheets. [doi:10.2320/matertrans.MT-M2020312]
\end{abstract}

(Received September 29, 2020; Accepted February 4, 2021; Published March 26, 2021)

Keywords: scanning microbeam small-angle scattering, interface microstructure, multilayered aluminum-alloys, interdiffusion, composite alloy sheets, strengthening mechanism

\section{Introduction}

\subsection{Clad materials}

Clad materials have been widely used to mitigate the shortcomings experienced when using single materials in various applications, e.g., controlling corrosion in aircraft, reducing weight in automotives, ${ }^{1)}$ and insulating radiation in nuclear plants. These clad materials contain interfaces introduced through the manufacturing process of bonding raw materials together. After the process, their mechanical properties in the aforenoted interface regions may be different from those of the raw materials. As such, it is important to investigate the variation in microstructure and accompanying mechanical properties in the interface region.

The manufacturing process of a clad material includes an interdiffusion process, which transforms interfaces into an interdiffusion layer with a width of the order of 10-100 $\mu \mathrm{m}$. In this diffusion layer, each local composition varies with position, resulting in variations both in the separated phases and the distributions of nanostructures with respect to position. This in turn leads to the variation in the mechanical properties within the layer. As such, to gain an in-depth understanding of the mechanical properties in the interface region, quantitatively investigating the nanostructure distribution of the interdiffusion layer is necessary. However, no sufficient research has been carried out in this area because examining nanostructures over a macroscopic region in a nondestructive and qualitative manner is difficult.

\subsection{Relationship between local structure and hardness}

In the $\mathrm{Al}-\mathrm{Zn}-\mathrm{Mg}$ alloy, precipitation strengthening is the principal strengthening mechanism; ${ }^{2-6}$ furthermore, this

\footnotetext{
${ }^{* 1}$ Graduate Student, Kyoto University. Corresponding author, E-mail lin.shan.72n@st.kyoto-u.ac.jp

*2Present address: Kobelco Research Institute, Inc., Kobe 651-2271, Japan
}

mechanism is related to the cut-through and Orowan mechanism. The structure obeys either one of the mechanisms is mainly under the condition of underaged or overaged, due to the time and strength relationship.

In a conventional study on age hardening, the identification of the relationship above by the observation of a transition from underage to overage under a constant volume fraction. However, for a composite in which the composition and phase separation varies within a span of area like an interdiffusion layer, it is difficult to confirm both the local composition and its local strength at once. Hence, we have to focus on the original explanation of the strengthening mechanisms and reconsider the identification method.

For by-passing and creating the Orowan loop ${ }^{7-9)}$ or hard precipitates, the increment of yield stress $\Delta \tau_{y}$ owing to the particle can be described by following Ashby-Orowan relationship $^{10)}$ and since $\mathrm{L} \gg r>b$, we have

$$
\Delta \tau_{y} \propto L^{-1} \approx \sqrt{n_{s}} \propto V_{f}^{0.5} / r
$$

where $L$ is the average distance of precipitates, $r$ is the average radius of obstacles, $b$ is the Burgers vector, $n_{s}$ is the obstacles per unit area in the by-passed plain, $V_{f}$ is the volume fraction of precipitates. The proportional constant depends on the lattice and mechanical properties of the matrix.

The mechanism of dislocation cutting through the precipitation is complicated:6,8)

Stacking fault strengthening, ${ }^{11)}$ modulus hardening, ${ }^{12)}$ coherency strengthening, ${ }^{2,13)}$ order strengthening ${ }^{14-16)}$ are proportional to $V_{f}{ }^{0.5} r^{0.5}$. Chemical hardening, ${ }^{2)}$ however, does not obey this rule, but appeared to be an insignificant mechanism. ${ }^{7,17)}$

Thus, the Orowan mechanism can be regarded as proportional to $V_{f}^{0.5} / r$ and $1 / L$, and the cut through mechanism as proportional to $V_{f}^{0.5} r^{0.5}$. So, it is plausible to evaluate the strength increment effected by aging using 
Table 1 Chemical Compositions of the layers.

\begin{tabular}{cccccccc} 
& \multicolumn{1}{c}{} & & & & $(\mathrm{mass} \%)$ \\
Layers & $\mathrm{Si}$ & $\mathrm{Fe}$ & $\mathrm{Cu}$ & $\mathrm{Mg}$ & $\mathrm{Zn}$ & $\mathrm{Ti}$ & $\mathrm{Al}$ \\
\hline $\mathrm{A} 1-\mathrm{Mg}$ & 0.016 & 0.014 & 0.005 & 2.45 & 0.001 & 0.01 & $\mathrm{bal}$. \\
\hline $\mathrm{Al}-\mathrm{Zn}$ & 0.014 & 0.017 & 0.005 & 0.00 & 10.16 & 0.01 & bal. \\
\hline
\end{tabular}

(a)

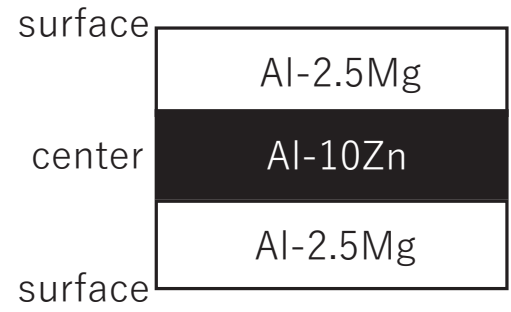

( b )

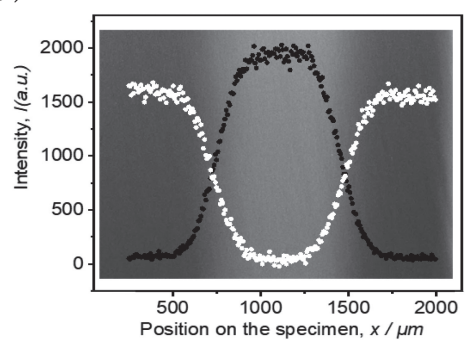

Fig. 1 (a) Configurations of the aluminum alloy sheet with a three-layered structure. (b) SEM image with measured fluorescent X-ray of $\mathrm{Zn}$ (black) and $\mathrm{Mg}$ (white).

a single formula for each of the mechanisms, disregarding whether the volume fraction is a constant or not.

In the previous study, we examined the nanostructure distribution and local mechanical properties in the interdiffusion layer of a clad sheet of model Al/Al-15.4 mass $\% \mathrm{Zn} / \mathrm{Al} .{ }^{18)}$ Sato et al. ${ }^{19)}$ investigated an Al-cladded composite with an inhomogeneous nanostructure distribution by small angle X-ray scattering (SAXS) analysis using scanning micro beam method.

In this study, we investigated the variation of nanostructure distribution and hardness in the interdiffusion layers of clad $\mathrm{Al}-2.5$ mass $\% \mathrm{Mg} / \mathrm{Al}-10$ mass $\% \mathrm{Zn} / \mathrm{Al}-2.5$ mass $\% \mathrm{Mg}$ alloy composites via a combination of scanning micro beam (for SAXS analysis), TEM (for direct observation), and micro Vickers (for hardness tests) analyses.

\section{Sample Preparation and Its Property}

\subsection{Sample structure}

Three-layered sandwich composite sheets comprising Al2.5 mass $\% \mathrm{Mg}$ alloy layers and an Al-10 mass $\% \mathrm{Zn}$ alloy layer were studied. Table 1 shows the detailed chemical compositions of the three layers. As shown in Fig. 1(a), the $\mathrm{Al}-\mathrm{Mg}$ alloys were on the surfaces sandwiching the $\mathrm{Al}-\mathrm{Zn}$ alloy.

Before cladding, each layer was heated to $723 \mathrm{~K}$ for $4 \mathrm{~h}$ for homo-genization and then cooled with air. Hot rolling at a temperature of $673 \mathrm{~K}$ was conducted, thereby reducing sheet thickness from $46 \mathrm{~mm}$ to $2.5 \mathrm{~mm}$, and the sheets were finally cold rolled to $2 \mathrm{~mm}$. After polishing the surface via wire buffing to remove the oxides, the three metal sheets were combined and hot rolled into the composite from an original thickness of $6 \mathrm{~mm}$ to a thickness of $3 \mathrm{~mm}$, at a temperature of $573 \mathrm{~K}$. Interdiffusion treatment was carried out at $673 \mathrm{~K}$ for $1 \mathrm{~h}$, and then the composites were cooled in a furnace. Final cold rolling was performed to reduce the thickness to $2 \mathrm{~mm}$.
Furthermore, $\langle 100\rangle$ texture in the normal direction, known as cube texture, forms in the rolled FCC sheet metals after annealing and recrystallization. ${ }^{20)}$

\subsection{Heat treatment}

To control the width of the interdiffusion layers developed from the interfaces, interdiffusion processes were conducted by annealing the composite at $793 \mathrm{~K}$ for $14.4 \mathrm{ks}$ or $57.6 \mathrm{ks}$ in a salt bath and then quenching it in iced water. Figure 1(b) shows the distribution of the X-ray fluorescence spectra of $\mathrm{Zn}$ and $\mathrm{Mg}$ in the composite, obtained via energy dispersive X-ray spectroscopy (EDX), after annealing for $14.4 \mathrm{ks}$. The obtained results show that solute concentrations, as well as the fluorescent X-rays intensities, are described by error functions. The interdiffusion layer thickness, determined based on the slope at the inflection point, was approximately $2.5 \times 10^{2} \mu \mathrm{m}$ and $4.8 \times 10^{2} \mu \mathrm{m}$ for $14.4 \mathrm{ks}$ and $57.6 \mathrm{ks}$ annealing, respectively. From this result, the interdiffusion layer with a thickness of $8.9 \times 10^{1} \mu \mathrm{m}$ was calculated to be formed during the cladding process.

Specimens were aged at $393 \mathrm{~K}$ in a silicon oil bath for $5 \mathrm{~min}, 3 \mathrm{~h}$, and 4 days, followed by iced water quenching. Figure 2 shows the composition of the present multilayer specimen mapped on a calculated equilibrium $\mathrm{Al}-\mathrm{Mg}-\mathrm{Zn}$ ternary phase diagram via the CALPHAD method.

The interdiffusion layer can be divided into several regions based on phase coexistence equilibrium using the ratio $\mathrm{Zn}($ at $\%) / \mathrm{Mg}($ at $\%)$. The $\eta$ phase precipitates from $\mathrm{Zn} / \mathrm{Mg}=$ 1 ; the $\mathrm{T}$ phase does not exist from $\mathrm{Zn} / \mathrm{Mg}=1.5$; and when $\mathrm{Zn} / \mathrm{Mg}$ is 6 , stable precipitation of the $\beta$ phase starts. The miscibility line of $\eta+\beta$ cannot be observed quantitatively in this phase diagram. Hence, the plots representing local structures on the specimen transverse different stable phase triangles and tie-lines, indicating that, unlike the binary alloy composite in the previous study, ${ }^{18)}$ where the same phase separation occurred within the whole interdiffusion layer, 


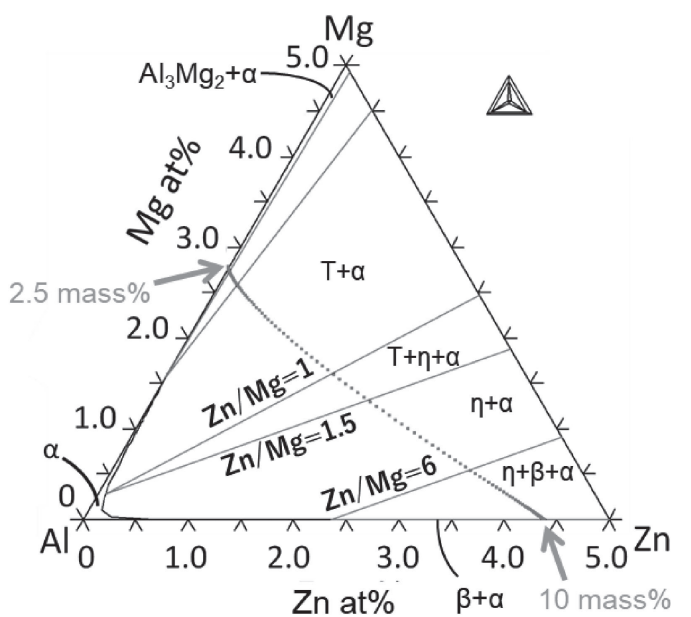

Fig. 2 Al-Zn-Mg ternary phase diagram at Al corner at $393 \mathrm{~K}$.

multiple phase separations may occur within this ternary composite, with respect to the local position and its $\mathrm{Zn} / \mathrm{Mg}$ ratio. The volume fraction also varies in turn.

\section{Experiment Procedure}

Micro beam scanning SAXS measurements were conducted at BL 40XU in Super Photon ring-8 GeV (SPring-8) in Hyogo, Japan. The experimental details were the same with the previous study. ${ }^{18)}$ A high-flux X-ray beam that was $5 \mu \mathrm{m}$ in diameter, with an energy of $15 \mathrm{keV}$, was used as the incident beam. The beam was shaped into $5 \mu \mathrm{m}$ via double pinhole system, as shown in Fig. 3.

Vickers hardness tests were performed as carried out in the previous report ${ }^{18)}$ to measure the local hardness distribution around the interdiffusion area of the specimens that had been aged for $5 \mathrm{~min}$ and $3 \mathrm{~h}$.

To understand the origin of weak anisotropic scattering observed for a longer annealing time, a TEM micrograph was

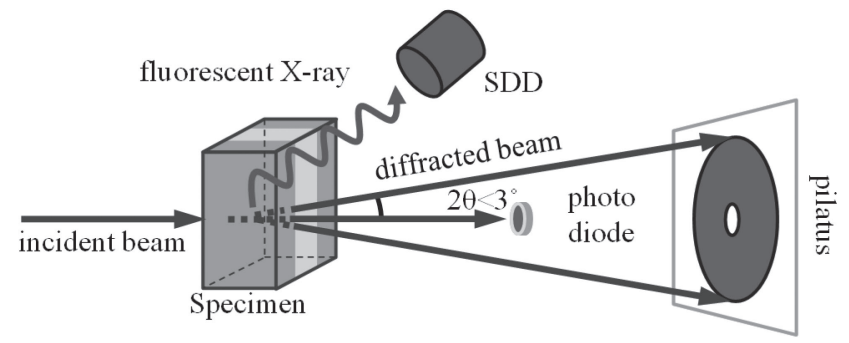

Fig. 3 Illustration of SAXS scattering devices.

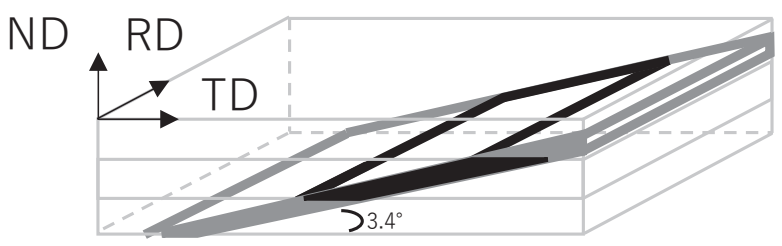

Fig. 4 TEM specimen manufactured from the cladded sheet composite. One of the interdiffusion layers was placed in the center.

obtained. The 2-mm-thick sandwich composite was cut off from the 3-layered cross-section and polished such that it had a slight slope with an angle of $3.4^{\circ}$ and an approximate thickness of $100 \mu \mathrm{m}$, as schematically shown in Fig. 4. Hence, the $4.8 \times 10^{2} \mu \mathrm{m}$ layer interdiffused for $14.4 \mathrm{ks}$ was spread to approximately $7000 \mu \mathrm{m}$. An area with a diameter of $3 \mathrm{~mm}$ was cut off from the layer and chemically polished for TEM observation.

After the TEM observation, another SAXS measurement was performed on the same specimen at Photon Factory in Ibaraki, Japan. An X-ray beam with a diameter of $1.5 \mathrm{~mm}$ was used. The scattering profile shows the averaged information of almost the whole TEM specimen.

\section{Results and Discussion}

\subsection{SAXS result and local hardness}

\subsubsection{Local structure in the diffusion layer}

In this work, radially averaged intensities were mainly used, as 2D SAXS patterns are almost isotropic, as shown in Fig. 5(a). The background and incident/transmitted X-rays were calibrated using beam monitors. The integrated intensity $Q$, Guinier radius $R_{g}$, and if the interference between precipitates was observed, averaged precipitation distance $L$ was calculated from the SAXS intensities. ${ }^{21)}$

$$
\begin{aligned}
& \text { Integrated intensity, } Q \text { : } \\
& \qquad \int_{0}^{\infty} q^{2} I(q) d q=2 \pi^{2} \Delta \rho^{2} V_{f}\left(1-V_{f}\right)
\end{aligned}
$$

where $q=4 \pi \sin \theta / \lambda$ is the scattering vector, $I(q)$ is the scattered intensity at $q, \Delta \rho$ is the electron density difference between the precipitate and matrix, and $V_{f}$ is the volume fraction of the precipitates. When $V_{f}$ is low, $Q$ can be approximated as $V_{f} \Delta \rho^{2} . R_{g}$ is the radius of gyration, calculated via the well-known Guinier's plot. $L$ was calculated using $L=2 \pi / q_{m} . q_{m}$ is where $I\left(q_{m}\right)$ is a local maximum.

Figure 6(a) shows the $Q, R_{g}$, and $L$ measured in the composite after aging for $5 \mathrm{~min}$ and $3 \mathrm{~h}$. Notably, $Q$ increased
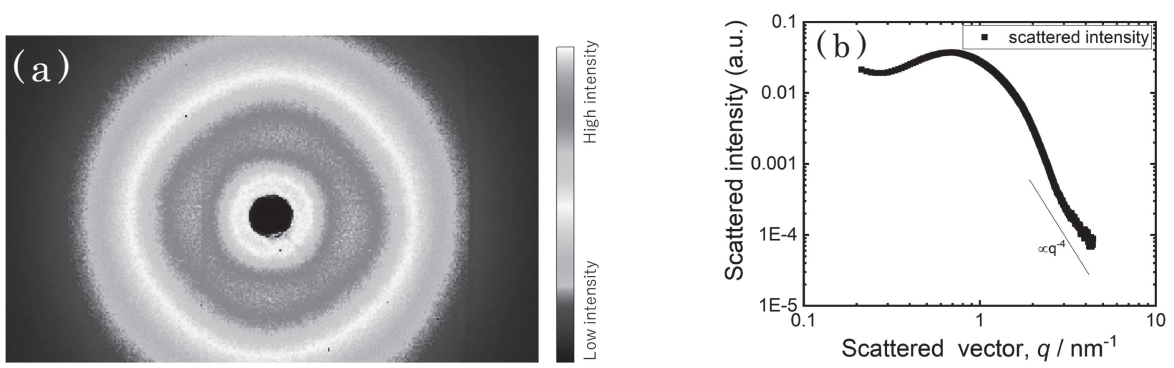

Fig. 5 Example of (a) 2D SAXS profile and (b) radially averaged profile. 

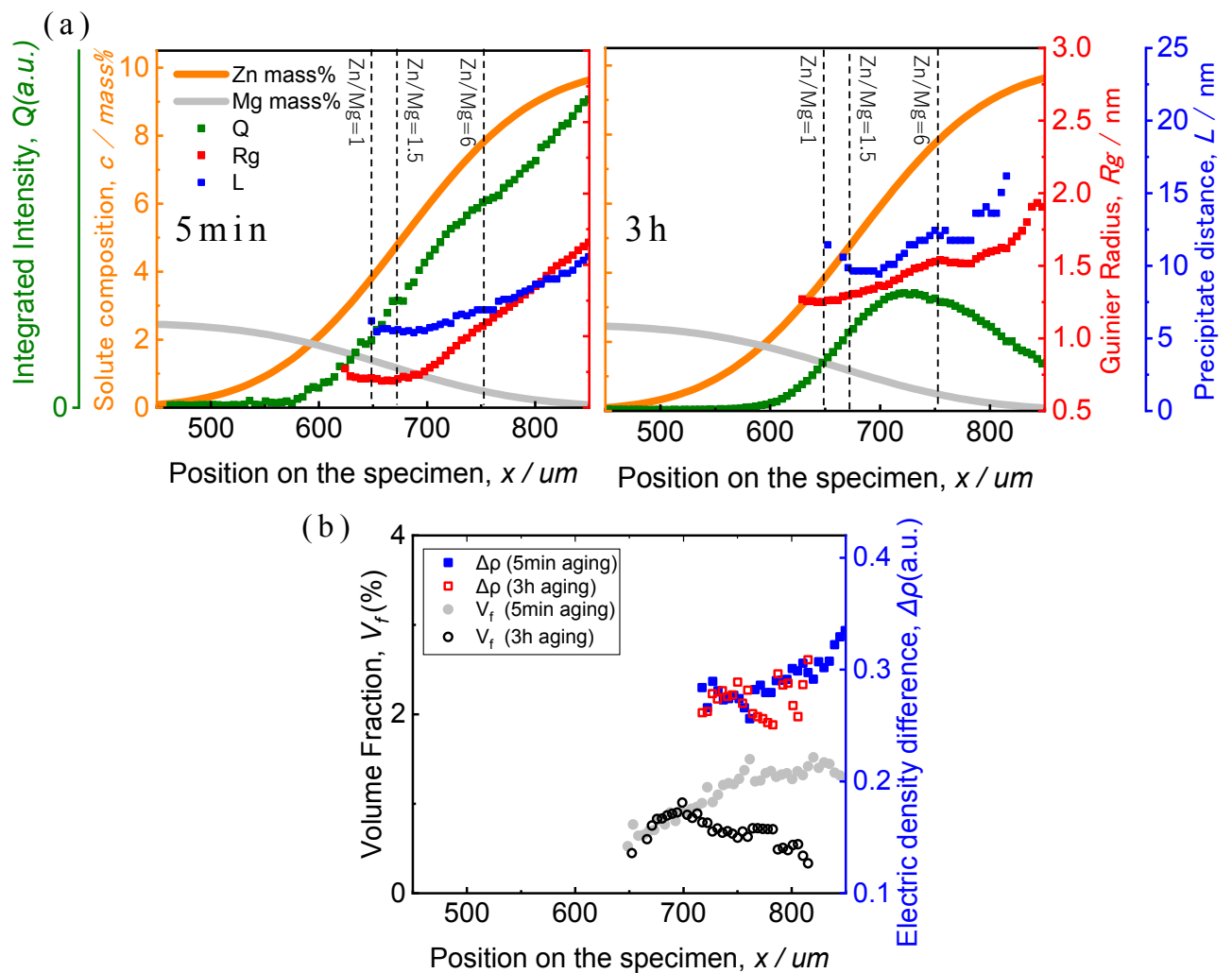

Fig. 6 Result of (a) SAXS parameters and (b) volume fraction and electron density difference for specimens after aged at $393 \mathrm{~K}$ for 5 min and $3 \mathrm{~h}$.

with the $\mathrm{Zn}$ concentration in the composite aged for $5 \mathrm{~min}$. Contrarily, in the composite aged for $3 \mathrm{~h}, Q$ decreased with an increase in the $\mathrm{Zn}$ concentration from approximately $700 \mu \mathrm{m}$ position on the specimen. $Q, R_{g}$, and $L$ also increased with the $\mathrm{Zn}$ concentration.

The scattering intensity $I(q)$ and $Q$ are affected by $\Delta \rho$ and the anisotropy of the precipitates. Anisotropy can be evaluated qualitatively from a $2 \mathrm{D}$ scattered pattern if the scatterers are exceedingly anisotropic and therefore need to be considered.

However, 2D scattered patterns corresponding to the composites aged for $5 \mathrm{~min}$ and $3 \mathrm{~h}$ were isotropic, as shown in Fig. 5. This indicates that the precipitates are accurate with a spherical shape. Hence, anisotropy can be ignored in this discussion.

$\Delta \rho$ affects $I(q)$ and $Q$ in the squared form, as indicated by eq. (2). Therefore, $\Delta \rho$ in the region in which several types of precipitates coexisted was estimated as the average value of $\Delta \rho$ for all precipitates. Since $\mathrm{Al}$ and $\mathrm{Mg}$ are located beside each other in the periodic table, $\mathrm{Al}_{3} \mathrm{Mg}_{2}$ was not observed from SAXS measurement. This can be confirmed from the fact that no appreciable SAXS intensity was observed in the region corresponding to the $\mathrm{Al}-\mathrm{Mg}$ alloy or before the $570 \mu \mathrm{m}$ position on the specimen. In other words, the measured precipitates are only $\mathrm{T}, \eta$, and $\beta$ for the stable phase and related metastable precursors.

Figure 6(b) shows the volume fraction and $\Delta \rho$ calculated from SAXS parameters and eq. (2). The electron density difference before position of $700 \mu \mathrm{m}$ on the specimen was not discussed owing to insufficient data accuracy at low $Q$ values. This indicates that the volume fraction slightly increased between $650 \mu \mathrm{m}$ and $700 \mu \mathrm{m}$, and decreased after $700 \mu \mathrm{m}$ on the specimen. Adachi et al. ${ }^{22)}$ showed a similar tendency while traversing the same stable phase area of $\alpha+\mathrm{T}+\eta / \alpha+\eta$ and $\alpha+\mathrm{T}$ aged at $393 \mathrm{~K}$ for $108 \mathrm{ks}$, but they did not obtain adequate results. The electron density also decreased at most to $89 \%$ at the $782 \mu \mathrm{m}$ position under aging from $5 \mathrm{~min}$ to $3 \mathrm{~h}$. This value is close to the difference in the electron density difference, of G.P. Zone/matrix and $\eta^{\prime} /$ matrix, calculated by Adachi et al. ${ }^{22)}$ to be $84 \%$. In addition, the electron density result and $\mathrm{Zn}$ concentration curve corresponding to aging for $5 \mathrm{~min}$ shows an approximately linear relationship and can be explained based on the G.P. Zone miscibility gap calculated by Adachi et al. ${ }^{22)}$

\subsubsection{Local hardness in the interdiffusion layer}

Figure 7(a) shows the Vickers hardness result corresponding to composites that underwent aging for $5 \mathrm{~min}$ and $3 \mathrm{~h}$. The HV distributions have the same tendency of increasing from $56 \mathrm{HV}$ as $\mathrm{Zn}$ concentration (or $\mathrm{Zn} / \mathrm{Mg}$ value) increases from approximately $620 \mu \mathrm{m}$ on the specimen; furthermore, they show peak hardness values of $111 \mathrm{HV}(5 \mathrm{~min})$ and $104 \mathrm{HV}(3 \mathrm{~h})$ between position of $700 \mu \mathrm{m}$ and $800 \mu \mathrm{m}$. With the aging progressing, the micro Vickers hardness increased with annealing time between $520 \mu \mathrm{m}$ and $720 \mu \mathrm{m}$ and decreased with time after $720 \mu \mathrm{m}$ on the specimen, where the hardness is $95 \mathrm{HV}$.

\subsubsection{Local hardness and relationship with nanostruc- ture}

Figure 7(b) shows the local hardness values and the plots of $V_{f}^{0.5} R_{g}{ }^{0.5}$ and $1 / L$, corresponding to the cut-through mechanism and the Orowan mechanism multiplied by a common constant for the 5-min and 3-h-aged specimens. The 


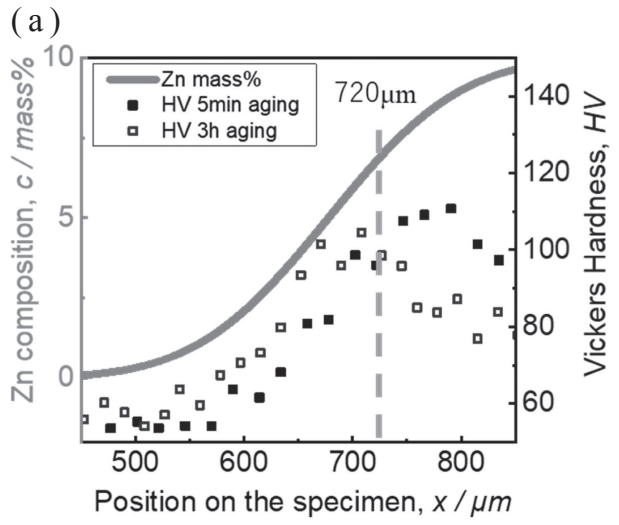

(b)
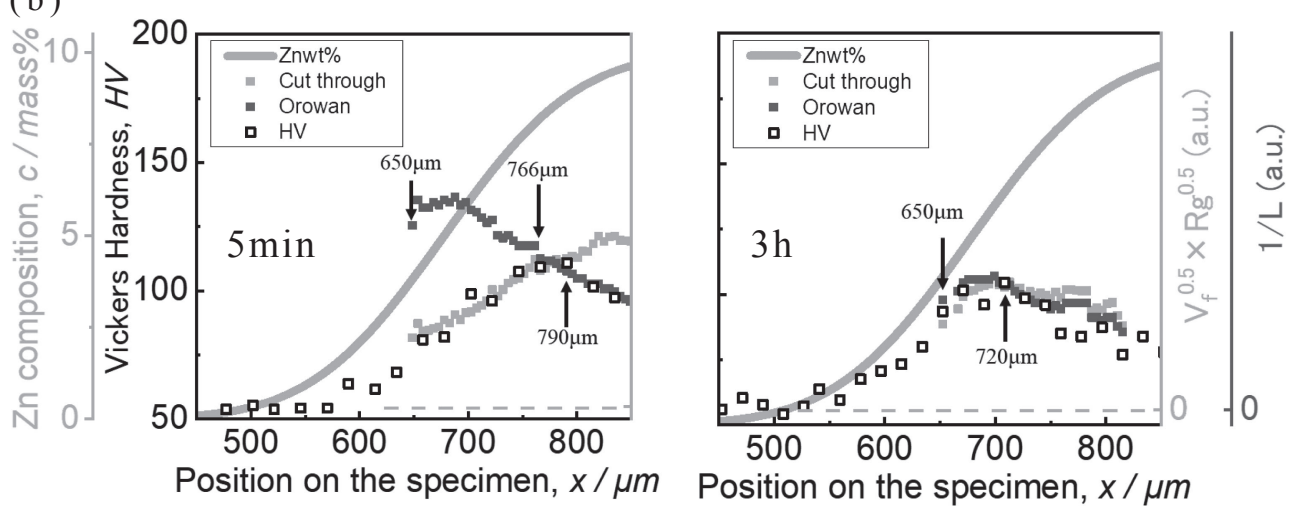

Fig. 7 (a) $5 \mathrm{~min} \& 3 \mathrm{~h}$ aged $\mathrm{HV}$ result and $\mathrm{Zn}$ distribution. Mg distribution is not shown. (b) Plots of different strengthening mechanisms on the specimen after aged at $393 \mathrm{~K}$ for $5 \mathrm{~min} \& 3 \mathrm{~h}$. Distribution of $\mathrm{Mg}$ is not shown.

plot of $V_{f}^{0.5} / R_{g}$ was similar to that of $1 / L$, indicating the validity of $V_{f}$. A common coherent strain for the cut-through mechanism and a common shear modulus for the Orowan mechanism are assumed for all regions of the plots. The plots of the either mechanism were adjusted to the hardness data as in the former report. ${ }^{18)}$ Since the Al-Mg alloy with low $\mathrm{Mg}$ concentration can only be strengthened by a solid solution and work hardening, ${ }^{22)}$ also the local hardness did not change from $56 \mathrm{HV}$ in the low $\mathrm{Zn}$ area before $570 \mu \mathrm{m}$ on the specimen, where $Q$ starts to raise from 0 . This indicates that the strength increment from solid solution in this material is low; thus, the effect of solid solution was ignored and a hardness of $54 \mathrm{HV}$ was considered without precipitation strengthening.

For 5-min aging, the cut-through mechanism plots can only be adjusted in the area within $650 \mu \mathrm{m}$ to $790 \mu \mathrm{m}$ on the specimen; for the Orowan mechanism, the plots can be adjusted in areas beyond $766 \mu \mathrm{m}$ on the specimen. Thus, the area within $766 \mu \mathrm{m}$ to $790 \mu \mathrm{m}$ can be adjusted using either of the mechanisms. For $3 \mathrm{~h}$ aging, both the mechanisms can roughly be fitted to the entire local hardness distribution, but in the area $708 \mu \mathrm{m}$ to $834 \mu \mathrm{m}$, the difference in the plots from mechanisms is trivial. As discussed in Section 4.1.3, it can be concluded that for the 5 min-aged composite, the structure before $766 \mu \mathrm{m}$ is underaged and that after $790 \mu \mathrm{m}$ is overaged. For the $3 \mathrm{~h}$-aged composite, the structure after $720 \mu \mathrm{m}$ is overaged.

\subsection{Local precipitates within interdiffusion layers}

As mentioned in Section 4.1.2, only $\mathrm{T}, \eta, \beta$, and the related metastable precipitates $^{23}$ ) can be detected using X-ray.
Moreover, since metastable phases are predominant in strengthening, ${ }^{24)}$ the aforementioned precipitates should be discussed.

In the specimen area of $\mathrm{Zn} / \mathrm{Mg}<1$, where the structure separates into $\alpha+\mathrm{T}$ (stable), the local hardness increased with annealing time. The results of thorough analyses of $\mathrm{T}$ and $\mathrm{T}^{\prime}$ are inadequate for identifying the nanostructure. ${ }^{25-27)}$

For the area of $1<\mathrm{Zn} / \mathrm{Mg}<1.8$, where the structure separates into $\alpha+\mathrm{T}+\eta$ (stable), Li et al. ${ }^{28)}$ have shown that phase segregation is faster in an alloy which has a higher $\mathrm{Zn} / \mathrm{Mg}$ ratio. Moreover, based on the work of Kovács et al. ${ }^{29)}$ and Maloney et al., ${ }^{30)}$ since 5-min and 3-h-aged structures are not overaged and isotropic, the precipitates are considered to be G.P. Zone or the early stage of $\eta^{\prime}$. It is known that $\eta^{\prime}$ strengthens $\mathrm{Al}-\mathrm{Mg}-\mathrm{Zn}$ alloys the most. ${ }^{24,29,31,32)}$ Therefore, the increase in hardness with aging time could be caused by either the coarsening of the G.P. Zone or the transformation into $\eta^{\prime}$.

The area $1.8<\mathrm{Zn} / \mathrm{Mg}<6$, where the structure separates into $\alpha+\eta$ (stable), is considered exists G.P. Zone and $\eta^{\prime}$ phase, according to the discussions about underaging and overaging in Section 4.1.3.2.

In the area $\mathrm{Zn} / \mathrm{Mg}>6$, where the structure separates into $\alpha+\beta$ (stable) and where $\mathrm{Mg}$ is diluted, analogous with the Al-Zn binary alloy, the phase separation of $\beta$ phase in the $\mathrm{Al}-\mathrm{Zn}$ binary at $393 \mathrm{~K}$ can be illustrated as:

$$
\begin{aligned}
\text { Solid Solution } & \rightarrow \text { G.P. Zone (sphere) } \\
& \rightarrow \text { G.P. Zone (ellipsoidal) } \rightarrow \alpha_{\mathrm{R}}^{\prime} \rightarrow \beta^{33)}
\end{aligned}
$$

Since the spherical and ellipsoidal G.P. Zone are extremely sensitive to quench speed, and because no anisotropic pattern 

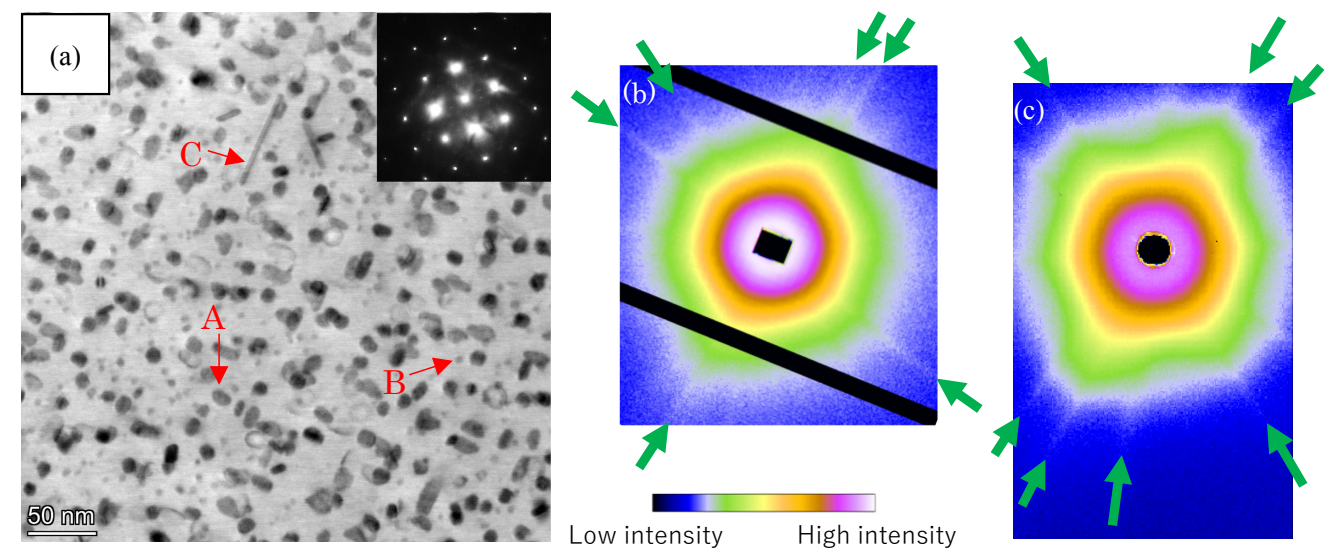

Fig. 8 (a) Angular Bright-Field (ABF) STEM image and diffracted pattern observed in the [100] direction at interdiffusion layer after aging at $393 \mathrm{~K}$ for 4 days. (b) 2D SAXS pattern of the TEM specimen. (c) 2D micro scanned SAXS pattern of the structure 7.0 mass $\% \mathrm{Zn}-0.75$ mass $\% \mathrm{Mg}$ on the composite after aging at $393 \mathrm{~K}$ for 4 days. Black lines in (b) are the detector modules.

was observed in SAXS, the precipitation of this sequence would be $\alpha_{R}^{\prime}$, with a sub-micrometer size, which cannot be observed in the SAXS 2D pattern. This is considered to cause the decrease in $V_{f}$ and $Q$ with aging time, as shown in Fig. 6(a) and (b).

\subsection{Anisotropy observation via TEM and SAXS profile}

It is known that both $\eta^{\prime}$ and $\eta$ occur in a variety of shapes; thus, radial averaging of 2D scattered intensities into 1D profiles will not accurately reflect the dimensions of the anisotropic precipitates. This leads to a deviation between the true $R_{g}$ and $V_{f}$, and the measured $R_{g}$ and $V_{f}$ without knowing the $3 \mathrm{D}$ shape.

Figure 8(c) shows an example of 2D scattered SAXS pattern which shows anisotropy. This pattern was observed on the specimen aged at $393 \mathrm{~K}$ and for a longer period of 4 days, at the position of specimen where has a concentration of 7.0 mass $\% \mathrm{Zn}$ and 0.75 mass $\% \mathrm{Mg}$. With this concentration, the structure separates into $\eta+\alpha$ (stable) in the ternary phase diagram showed on Fig. 2. The anisotropy observed can roughly be divided into 2 types, i.e. the streaks which are weak and thin, indicated with green arrows; and a polygonal pattern. To examine the origin of these anisotropies, a TEM observation was conducted with a specimen underwent the same heat treatment of $393 \mathrm{~K}$ for 4 days, and a 2D SAXS measurement was also performed on this TEM specimen. Both measurements were conducted at the same projection direction with it of original SAXS measurement in Fig. 8(c). Figure 8(a) shows the observed Angular Bright-Field (ABF) STEM image and its diffracted pattern showing $\langle 100\rangle$ projection. In this image, there are three types of precipitates observed from its shape: $\eta^{\prime}$ phase denoted as A, G.P. Zone as $\mathrm{B}$, and $\eta$ phase as $\mathrm{C}$, according to the results obtained by S. Jacumasso et al. ${ }^{34)}$

Figure 8(b) shows the 2D SAXS pattern of the TEM specimen derived from an X-ray projected the same $\langle 100\rangle$ orientation with the dark-field image. The pattern has a polygonal shape with multiple weak streaks showed with green arrows. This can be explained by a combination of large isotropic patterns scattered from the small spherical B, oblate shapes scattered from the oblate-shaped $\mathrm{A}$, and the small amount of long rod-shaped $\mathrm{C}$ scattered into thin discs, which were cut into thin streaks by Ewald sphere. Hence, the $\mathrm{A}, \mathrm{B}$, and $\mathrm{C}$ precipitates can be confirmed with $\eta^{\prime} / \eta$ and G.P. Zone.

\section{Conclusion}

In this study, we performed several nondestructive distribution analyses in the interface region of $\mathrm{Al}-\mathrm{Mg} / \mathrm{Al}-$ $\mathrm{Zn} / \mathrm{Al}-\mathrm{Mg}$ composite sheets after artificial interdiffusion and aging treatments, via scanning microbeam SAXS measurement with a $10 \mu \mathrm{m}$ step and $0.5 \mathrm{~mm}$ span. Within the whole interdiffusion layer which is an Al alloy with spatially changing $\mathrm{Mg}$ and $\mathrm{Zn}$ compositions, we examined the nanostructure distribution in every $10 \mu \mathrm{m}$, and successfully explain the local hardness and their change at different position and aging time. We also discovered the nanostructure strengthened by the Orowan and cut-through mechanisms can be co-existed within a single interdiffusion layer of a composite, and the diffusion layer can be divided into area strengthened by either of the mechanism. The anisotropy in the 2D SAXS pattern was also succeeded in being interpreted with the combination of multiple anisotropic precipitates with TEM observation and research of precursors.

\section{Acknowledgments}

This research is based on the results obtained from a project commissioned by the New Energy and Industrial Technology Development Organization (NEDO). Part of the work has been supported by Grants-in-Aid for Scientific Research 18K18944 and Japan Aluminium Association R212. Synchrotron radiation experiments were performed at the BL40XU of Spring-8 with the approval of the Japan Synchrotron Radiation Research Institute (JASRI) (Proposal No. 2016A1168，2016B1275， 2016B1282， 2017B1570, 2017B1611, 2018A1591 and 2019A1639).

\section{REFERENCES}

1) A. Ito, Y. Iwai, T. Nagara, Y. Miyagi, H. Fujimoto and J. Takigawa: J. JILM 44 (1994) 246-252. 
2) L.M. Brown and R.K. Ham: Strengthening Methods in Crystals, (Elsevier, Amsterdam, 1971).

3) M.F. Ashby: Physics of Strength and Plasticity, (MIT Press, Massachusetts, 1969).

4) V. Gerold: Z. Met. 62 (1971) 796.

5) P.B. Hirsch: Atomic Structure and Mechanical Properties of Metals, (North-Holland, Amsterdam, 1976).

6) I. Kovás: Proc. X. Conf. Metallurgy and Material Testing, (1979) p. 37.

7) A.J. Ardell: Metall. Trans. A 16 (1985) 2131-2165.

8) T. Gladman: Mater. Sci. Technol. 15 (1999) 30-36.

9) Z. Guo and W. Sha: Mater. Trans. 43 (2002) 1273-1282.

10) M.F. Ashby: Oxide Dispersion Strengthening, (Gordon and Breach, New York, 1958).

11) V. Gerold and K. Hartmann: Trans. JIM 9 (Supplement) (1968) 509.

12) K. Hanson and J.W. Morris, Jr.: J. Appl. Phys. 46 (1975) 2378-2383.

13) B. Jansson and A. Melander: Scr. Metall. 12 (1978) 497-498.

14) P. Guyot: Philos. Mag. 24 (1971) 987-993.

15) R.K. Ham: Trans. JIM 9 (supplement) (1968) 52.

16) J.L. Castagné: J. Phys. 27 (1966) C3-233.

17) V. Gerold: Dislocations in Solids, (North Holland, Amsterdam, 1979)

18) S. Lin, H. Okuda, Y. Higashino, K. Matsumoto and K. Sato: Mater Trans. 61 (2020) 300-304.

19) K. Sato, K. Matsumoto and H. Okuda: Mater. Trans. 60 (2019) 254 262 .

20) W. Mao: J. Mater. Eng. Perform. 8 (1999) 556-560.

21) A. Guinier and G. Fournet: Small Angle Scattering of X-rays, (John
Wiley \& Sons, Inc., New York, 1955).

22) H. Adachi, K. Osamura and H. Okuda: J. Japan Inst. Metals 63 (1999) 733-740.

23) L.K. Berg, J. Gjønnes, V. Hansen, X.Z. Li, M. Knutson-Wedel, G. Waterloo, D. Schryvers and L.R. Wallenberg: Acta Mater. 49 (2001) 3443-3451.

24) J. Lendvai: Mater. Sci. Forum 217-222 (1996) 43-56.

25) T. Fukui, Y. Takeshima, S. Nakamura and Y. Baba: J. JILM 25 (1975) 459-466.

26) H. Suzuki, S. Asami and M. Kanno: J. JILM 23 (1973) 452-456.

27) X.B. Yang, J.H. Chen, J.Z. Liu, F. Qin, J. Xie and C.L. Wu: J. Alloy. Compd. 610 (2014) 69-73.

28) S. Lee, K. Watanabe, K. Matsuda, K. Nishimura, N. Numomura, H. Toda, K. Hitayama, K. Shimizu, H. Gao, T. Yoshida, S. Murakami and S. Ikeno: J. JILM 67 (2017) 162-167.

29) I. Kovács, J. Lendvai, T. Ungar, G. Groma and J. Lakner: Acta Metall. 28 (1980) 1621-1631.

30) S.K. Maloney, K. Hono, I.J. Polmear and S.P. Ringer: Scr. Mater. 41 (1999) 1031-1038.

31) J.K. Park and A.J. Ardell: Metall. Trans. A 14 (1983) 1957-1965.

32) K. Osamura, S. Ochiai and T. Uehara: J. JILM 34 (1984) 517-524.

33) H. Löffer: Structure and Structure Development of Al-Zn Alloys, (Verlag, Akademie, 1995).

34) S.C. Jacumasso, J. de Paula Martins and A.L.M. de Carvalho: Rev. Esc. Minas 69 (2016) 451-457. 